\title{
PRIMAVERA: A SUSTENTABILIDADE COMO FOCO EM UMA COLEÇÃO DE JOIAS
}

\section{Silvana Beatriz Grappi}

contato@silvanagrappi.com.br

Resumo: Este projeto de protótipo consiste em uma coleção de joias, cujo objetivo é ser sustentável. Em pleno século XXI, a fabricação desses objetos ainda utiliza matéria prima e métodos não sustentáveis. $O$ design pode ajudar na mudança desta situação, projetando joias com baixo impacto ambiental e incentivando uma nova mentalidade de consumo. É a isto que este trabalho se propõe, ao utilizar galhos de árvores caídos aliados à prata, metal nobre, que confere status aos galhos. O estudo começou com um levantamento bibliográfico e visitas a sítios eletrônicos. Em seguida, foi escolhida a metodologia projetual de Bruno Munari. O resultado obtido com a coleção é a prova de que a sustentabilidade é possível com pequenos atos como, por exemplo, transformar um simples galho de árvore em um objeto de desejo.

Palavras-chave: Joia, sustentabilidade, conscientização.

Abstract: This prototype project consists of a jewelry collection whose objective is to be sustainable. In the 21st century, the manufacturing of these objects still uses raw materials and methods that are nonsustainable. The design can help to change this situation, conceiving jewelry with low environmental impact and encouraging new consumer mindset. This is what this work proposes by using branches of fallen trees combined with silver, a precious metal, which gives status to the branches. The study began with a bibliographical survey and visits to websites. Then, Bruno Munari's design methodology was selected. The result obtained with the collection is the proof that sustainability is possible by means of small acts, such as turning a simple tree branch into an object of desire.

Key - words: Jewel, sustainability, awareness. 


\section{1- INTRODUÇÃO}

"Primavera" é o nome da coleção de joias apresentada neste projeto. Com foco na sustentabilidade, ela é confeccionada com galhos caídos de onde nascem folhagens em prata. Este trabalho chama a atenção para um material aparentemente sem nenhuma utilidade, uma vez que seria fatalmente levado para o lixo. 0 uso da prata, um metal nobre, agrega valor aos galhos, o que poderia acontecer com qualquer outro material descartado diariamente, seja pela natureza ou pelo homem.

De acordo com a especializada em gestão ambiental, Marilena Lavorato (2016), "consumir é inevitável e necessário para a circulação de mercadorias e manutenção dos sistemas econômicos". No entanto, ainda segundo a autora, é preciso que se aprenda a consumir de forma consciente e equilibrada para que os recursos naturais da Terra não se esgotem. O impacto exercido pela atividade humana sobre o meio ambiente é cada vez maior e este já não é capaz de absorvê-lo. Isso ameaça o bem estar das futuras gerações (ASHBY, 2005, p. 418).

Por meio do design podemos incentivar o uso de novas tecnologias e a descoberta de formas limpas de produzir, além de conscientizar o consumidor com relação à utilização de materiais.

$\mathrm{O}$ designer tem que ser consciente de sua responsabilidade moral e social. $\mathrm{O}$ design é a arma mais poderosa que o homem recebeu para configurar o que produz, seu meio ambiente, e, por extensão, a si mesmo; com ela, deve analisar as consequências de seus atos, tanto do passado quanto do futuro previsível (PAPANEK, 1971, p. 94, tradução livre).

Ainda que o consumo desenfreado vigore na maior parte do mundo, já há uma tendência à sua redução: o lowsumerism, um movimento que se baseia em "consumir menos, buscar alternativas e viver apenas com o necessário", (BIZ, 2016). Ainda de acordo com o autor "o processo de autodestruição causado pelo consumismo só poderá ser freado por meio de um profundo despertar de consciência".

O objetivo deste trabalho é demonstrar, através dos protótipos da coleção "Primavera", que é possível desenvolver joias com foco na sustentabilidade, ou seja, ecologicamente corretas, socialmente justas, economicamente viáveis e culturalmente aceitas. A intenção é que a coleção desperte a reflexão e contribua com a mudança do gosto do consumidor, ajudando-o a pensar sobre a diminuição das injustiças trabalhistas e da agressividade provocada ao meio ambiente.

Para alcançar este objetivo, foi utilizada a metodologia desenvolvida pelo artista e designer italiano Bruno Munari (1981), que recomenda, em linhas gerais, a seguinte ordem de passos a seguir: definição do problema, divisão do problema em subproblemas, coleta de dados, análise dos dados compilados e análise de similares, experimentação dos materiais e técnicas disponíveis para o projeto, esboços, verificação e por último os desenhos técnicos. Foram fundamentais as orientações da Dra. Ana Beatriz Simom Factum durante todo o processo e da Universidade do Estado da Bahia por auxiliar com sua infraestrutura.

Os requisitos do projeto são inerentes à sustentabilidade que, no caso da joalheria, implica na utilização de metais reciclados e pedras ecologicamente corretas, tudo com origem certificada. Também é fundamental o emprego de processos de 
fabricação limpos, o uso de equipamentos de proteção individual (EPIs) e, com relação à madeira, o uso de materiais não agressivos à natureza em seu acabamento.

\section{2- DESENVOLVIMENTO}

Ainda hoje, parte do ramo joalheiro utiliza matéria prima oriunda de métodos ambientalmente incorretos e socialmente irresponsáveis, que deterioram o ecossistema e desestruturam comunidades próximas às minas. O garimpo de Serra Pelada talvez seja o mais conhecido exemplo dos frequentes e graves desastres socioambientais ocorridos no país, mas não é o único.

De acordo com uma matéria publicada na revista Carta Capital, "A Organização Internacional do Trabalho (OIT) considera o setor de mineração (de ferro, carvão, ouro, diamante etc.) como o mais perigoso do mundo para se trabalhar atualmente. As condições nestes ambientes são desumanas" (CARTA CAPITAL, 2016). Ainda segundo o texto, a Human Rights Watch (HRW) afirma que a situação do trabalho nas jazidas de ouro da Tanzânia é calamitosa. "Sem nenhuma fiscalização, o uso de mão de obra infantil é comum e não há nenhuma proteção aos trabalhadores". Injustiças trabalhistas nas extrações se repetem em diversos lugares, desde o continente africano (Tanzânia, Eritreia, Ghana, Moçambique), até países em estagio mais avançado de desenvolvimento como a Turquia e o Chile. Além da exploração e do desrespeito aos trabalhadores, com turnos que, segundo a revista, chegam a 24 horas, as condições precárias predispõem os mineradores a constantes ameaças à integridade física com acidentes sérios ou até fatais e doenças relacionadas ao contato com o mercúrio.

O impacto também é negativo para às comunidades em torno das jazidas. Ondas migratórias aumentam a pressão sobre a infraestrutura e serviços urbanos de pequenas cidades e, em muitos casos, intensificam a violência, o álcool, e a prostituição. As jazidas se tornam, segundo a revista, "paraísos para diversas atividades ilegais como lavagem de dinheiro, tráfico humano, de drogas e de armas".

Pouco se faz para reverter o cenário, pois todos querem manter o custo da extração, manuseio e transporte reduzido: os governos, as multinacionais e também os consumidores. A responsabilidade, de acordo com a matéria, "não é somente de um governo ou de uma empresa, mas de toda uma cadeia produtiva que requer baixíssimos gastos com mão de obra para se manter lucrativa".

Uma das mais importantes atividades econômicas da atualidade, a mineração é de grande importância para o funcionamento do mundo cotidiano. O ouro, por exemplo, não é usado só em joias, mas em diversos setores como o eletrônico, a aviação, a medicina e a odontologia, entre outros.

Segundo a Carta Capital, a mudança só poderá acontecer se as legislações trabalhistas forem mais rígidas nos países onde as extrações acontecem, mas, para isso, é importante a atuação da sociedade civil no sentido de buscar formas de fazer com que organismos internacionais como ONU, OIT, OMC e Banco Mundial e governos, pressionem os países em desenvolvimento para garantir o direito dos trabalhadores.

Os efeitos nocivos da mineração não param por ai. É um processo altamente prejudicial para a natureza que sofre modificações irreversíveis. A extração de minerais causa degradação paisagística, assoreamento de drenagens, fundos de vales e 
nascentes; contaminação das águas, risco de desmoronamentos, intensificação da erosão, poluição do ar, vibração do terreno e impactos sobre a flora e fauna. Estes danos foram confirmados pelo Centro de Tecnologia Mineral (CETEM) do Ministério da Ciência, Tecnologia e Inovação que estudou 105 territórios de 22 estados brasileiros.

As áreas exploradas pela mineração devem ser recuperadas com reflorestamento e reabilitação para o uso da agricultura e pecuária, mas infelizmente, algumas empresas abandonam o local ou plantam uma linha de árvores em frente escondendo as galerias. As atividades do setor precisam ser acompanhadas mais de perto pelos órgãos ambientais, com uma fiscalização mais severa. As cooperativas e os arranjos produtivos locais (APLS) precisam ser mais incentivados, pois integram questões ambientais, sociais e econômicas e tem grande potencial para melhorar 0 desempenho dos garimpos e minas.

Existem técnicas de extração limpas, mas elas são usadas apenas em pequena escala. Um exemplo é o "Ouro Verde", na Colômbia, que segundo matéria de Lorenzo Morales no site da BBC, detém os selos "Fair Trade" de Comércio Justo e de Mineração Justa. Estas classificações garantem nichos de mercado internacionais para a associação. "Os mineiros da Ouro Verde recebem $15 \%$ a mais por seu ouro, pagos pelos consumidores finais. O dinheiro vai para um fundo comunitário e é reinvestido em mineração ou dividido pelas famílias" (MORALES, 2011).

Ainda segundo o site, Cristina Echavarria, diretora da Aliança para a Mineração Responsável (AMR), organização global que ensina mineiros a usar o mercúrio e outros químicos com responsabilidade, diz que "O Ouro Verde é uma ideia maravilhosa, mas o problema é que o mercado demanda mais do que é possível produzir usando estes métodos". Para ela, é necessário um modelo de extração sustentável que inclua mais mineiros e a produção de mais ouro. O problema, segundo o blog do professor Omar Furst, Especialista em Educação Ambiental, é que muitos governos não incentivam a extração artesanal; só a de grande escala.

Tudo isto acarreta a falta de conscientização, por parte da maioria dos profissionais envolvidos na cadeia produtiva. Uma grande mudança é necessária. Os fabricantes de joias, por exemplo, deveriam exigir um selo de garantia de qualidade do ouro e da prata. A busca de formas de produção cada vez mais limpas, a pesquisa que possibilite novas descobertas e a consequente mudança dos hábitos de consumo deveriam ser mais incentivadas.

Existem várias fontes para recuperação dos metais nobres: sucatas industriais, placas de circuito impresso, condutores, conectores, relês, centrais antigas de telefonia, computadores e catalisadores do escape dos veículos. A prata também pode ser reutilizada a partir de radiografias, mas deve-se prestar atenção aos métodos usados que podem ser agressivos para o meio ambiente. As grandes oficinas de joias mandam para a recuperação a varredura do chão, das politrizes, escovas, lixas e a água da lavagem das mãos.

\section{1- Limitantes}

A primeira restrição encontrada tem relação com a matéria prima. A maior parte da prata fornecida não possui selo de certificação e quem compra se vê obrigado a acreditar na palavra do fornecedor. Com respeito aos galhos de árvores, dependendo da madeira, há necessidade de uso de fungicida, mas este pode ser natural, sem químicos. A pilotagem, no caso do presente projeto, é feita artesanalmente, o que 
requer paciência e depende de um profissional competente para manusear o metal. Há necessidade de uso de produtos químicos, tóxicos e agressivos ao meio ambiente que após a utilização devem ser descartados da maneira adequada. As soluções básicas e ácidas precisam ser neutralizadas. Devem ser usados equipamentos de segurança como óculos, máscaras e luvas.

\section{2- Metodologia de Desenvolvimento}

"O método projetual não é mais do que uma série de operações necessárias, dispostas por ordem lógica, ditada pela experiência. O seu objetivo é o de se atingir o melhor resultado com o menor esforço" (MUNARI, 1981, p. 18). Como dito anteriormente, Munari recomenda começar com a definição do problema, que, neste caso, é a criação e a produção de joias ecologicamente corretas.

Em seguida, devem ser determinados os limites dentro dos quais o projetista irá trabalhar: estabelecer as características do produto e o tipo de solução que se quer atingir, pois, um problema pode ter várias saídas. A proposta deste projeto foi criar uma coleção composta de anéis, colares e brincos para serem usados em ocasiões especiais, por pessoas que queiram usar e ressaltar sua escolha por joias visivelmente amigas da natureza. O metal escolhido foi a prata que possibilita um produto com um preço mais acessível do que o do ouro.

Durante o processo de criação surgiram várias ideias de materiais que poderiam ser associados à prata como galhos de árvore caídos, madeira de demolição, pedras brutas sem valor comercial, alumínio reciclado, circuitos eletrônicos, papel machê, etc. Os galhos foram escolhidos por seus belos e variados formatos e pela harmonia na junção com o metal.

Segundo Munari, definido o problema, é necessário desmontá-lo em seus componentes ou subproblemas para melhor conhecê-lo e simplificar a resolução. No presente projeto, a divisão em itens fez surgirem vários aspectos que devem ser levados em consideração: público alvo, técnicas de elaboração, sequência de atividades, aspectos ergonômicos, sistemas de fixação, acabamentos e cores, entre outros. A intenção da coleção "Primavera" é a de criar adornos que identifiquem o usuário como pessoas ambientalmente conscientes. São joias que não seguem uma moda ou gostos do momento, e, por usarem um metal precioso, se espera que tenham longa durabilidade. Serão utilizadas técnicas artesanais oriundas de práticas sustentáveis, ao alcance da designer. As partes em prata serão elaboradas manualmente em uma oficina de ourives. A madeira será trabalhada em uma marcenaria.

Para se adaptar ao uso, as peças devem obedecer a certas exigências ergonômicas. Por exemplo, um orifício, para ser encaixado no dedo, deve ficar confortável. Da mesma maneira, as partes que podem machucar precisam receber acabamento.

Outros subproblemas necessitaram ser definidos como, por exemplo, o acabamento da prata que pode ser brilhante ou fosco, liso ou texturizado. Também devem ser determinados o tipo de fecho para os colares, de encaixes para os brincos e os sistemas de fixação entre a prata e a madeira para deixar as peças solidamente unidas. O tipo de madeira dos galhos precisa ser escolhido cuidadosamente, pois existem várias qualidades. Ela não pode conter fungos nem cupins e deve ser resistente para proporcionar peças duráveis. 
O autor indica fazer uma coleta de dados para conhecer cada detalhe do projeto separadamente principalmente com relação aos materiais usados e às técnicas disponíveis para cada parte do processo de fabricação. Recomenda também, fazer uma pesquisa com o intuito de documentar o que já foi feito de semelhante ao que se pretende projetar. A análise dos dados recolhidos permite observar como foram resolvidos certos subproblemas e desvendar defeitos nos similares existentes a fim de não repeti-los. Seguir estas instruções possibilitou ao designer maior senso crítico e capacidade de enxergar os pontos positivos e negativos do projeto.

Os designers de joias que servem como referência a este projeto têm seus trabalhos focados na sustentabilidade. Neles, assim como nesta coleção, são usados materiais ecologicamente responsáveis. Também são utilizadas práticas de manufatura ambientalmente corretas principalmente no que se refere ao cuidado com os produtos tóxicos utilizados no processo. O marketing é pautado na divulgação do conceito de sustentabilidade.

Alguns exemplos são a designer Mana Bernardes que utiliza o PET e, por meio de um design atraente, consegue sensibilizar o consumidor; Silvia Blumberg que usa prata reciclada de chapas radiográficas e resíduos de obras, como concreto e pó de tijolo; Arthur Lewis que faz um trabalho muito delicado com fundos de latas de alumínio; Miriam Mamber que, ao criar peças com fungos ao lado de ouro, sensibiliza para a riqueza dos materiais, fazendo as pessoas perceberem as necessidades de ampliarem suas consciências seletivas; Yoav Kotik que faz um trabalho pautado em novos valores ao chamar as tampinhas de garrafa de "metal precioso" e confere a estas, uma nova vida.

Ainda de acordo com Munari (1981, pg. 56), deve ser feita a experimentação de materiais e tecnologias que o designer tem à sua disposição para realizar o projeto. Dessa experimentação resultarão amostras, conclusões e informações que podem conduzir à solução dos subproblemas que, por sua vez, concorrerão para a solução global.

O manuseio do material e das ferramentas é imprescindível para que se conheça o seu comportamento. Neste trabalho foram testados vários tipos de serras: 0 arco de serra de ourives (Figura 1), serras manuais de carpinteiro e serra disco. 0 formão serviu para retirada da camada externa dos galhos, o córtex. Para o acabamento da madeira foi utilizada a lixadeira de bancada. A furadeira de bancada e a furadeira comum serviram para fazer os orifícios que permitem a passagem dos dedos nos anéis. $O$ motor de rabicho foi útil para dar acabamentos mais finos $\mathrm{e}$ precisos. A partir dos resultados encontrados no final desta etapa, várias formas foram sendo criadas e compostas (Figuras 2 e 3 ).

Quando os galhos foram serrados, surgiram furos gerados pelo cupim. Como há uma série de efeitos nocivos que os pesticidas químicos podem provocar sobre o meio ambiente, foi feita uma pesquisa sobre métodos naturais para combatê-lo e para preveni-lo, por exemplo, os óleos essenciais de laranja ou citronela misturados na cera.

Em seguida determinou-se o tipo de acabamento que seria dado à madeira. Foram usadas lixas de várias gramaturas e depois aplicado um selador para reduzir a porosidade, eliminar a absorção antes do acabamento e oferecer um efeito fosco à madeira. O produto usado contém menos químicos nocivos por ser à base de água, além dos copolímeros acrílicos em emulsão, biocidas não metálicos, agente fosqueante e aditivos. Não é totalmente biodegradável, portanto deve-se evitar que 
entre em contato com o solo e/ou a água. Ao selador foi misturado um tingimento, também à base de água, para dar uma tonalidade ligeiramente mais escura à madeira. Para finalizar, usou-se uma pasta feita com cera de abelha e de carnaúba. Além de servir para a conservação, protege os galhos contra a ação da umidade e da poeira.

Para Munari (1981, pg. 58), somente após descobrir as possibilidades técnicas, o comportamento do material e o aspecto adquirido, é possível estabelecer relações entre os dados recolhidos. Desta forma, a possibilidade de erros é reduzida. Neste momento pode se começar a elaborar alguns esboços gerando várias alternativas projetuais (Figura 4). O formato dos galhos foi determinante na criação dos modelos. Para testar o movimento das folhagens sobre os galhos, visualizar o efeito e definir formas, só os desenhos não foram suficientes. Por isso, foram criados recortes de papel que foram testados sobre a madeira (Figura 5).

A etapa seguinte consistiu na realização dos desenhos artísticos das seis peças da coleção (Figura 6). Segundo Munari (1981, pg.60), é necessário apresentar os modelos a prováveis usuários para ter um "feed back" a partir do qual o modelo pode ou não ser alterado.

No momento subsequente, foram realizados os desenhos técnicos, que são necessários para comunicar os dados para o ourives (Figura 7). "Estes desenhos serão executados de maneira clara e legível e em quantidade suficiente para se perceberem bem todos os aspetos" (MUNARI, 1981, p. 62).

A sequência de etapas para realização dos protótipos foi sendo determinada à medida que a necessidade foi surgindo e também com base na experiência da designer: o modus operandi determinando os procedimentos. A última etapa de desenvolvimento dos protótipos (Figuras 8 e 9) consistiu na modelagem das peças em prata ao redor da madeira, com o cuidado de não riscá-la e obter a melhor adaptação possível entre as partes.

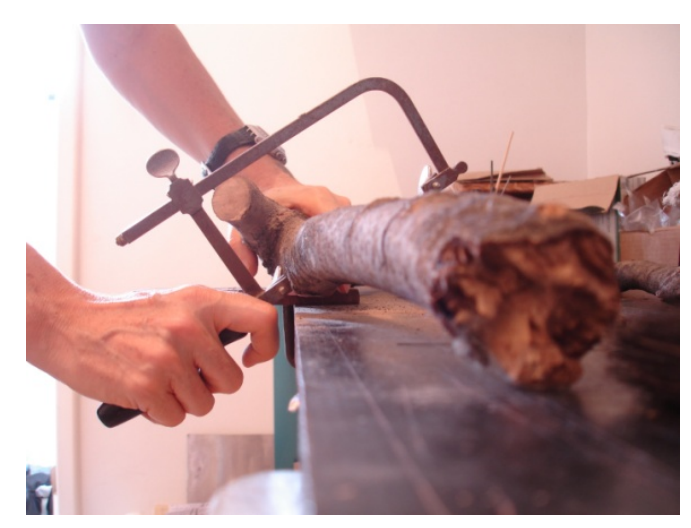

Figura 1. Serrando um galho de árvore com o arco de serra de ourives. Fonte: Elaborado pelo autor, com base na pesquisa realizada (2013). 

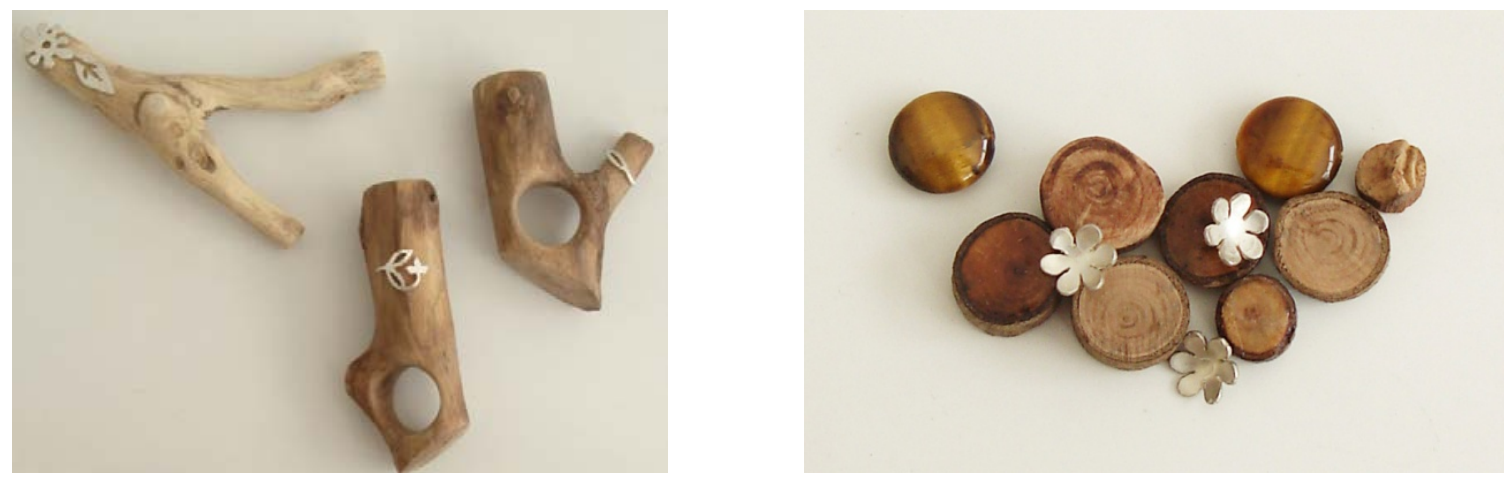

Figuras 2 e 3- Testando as formas de cortes dos galhos e das peças em prata.

Fonte: Elaborado pelo autor, com base na pesquisa realizada (2013).

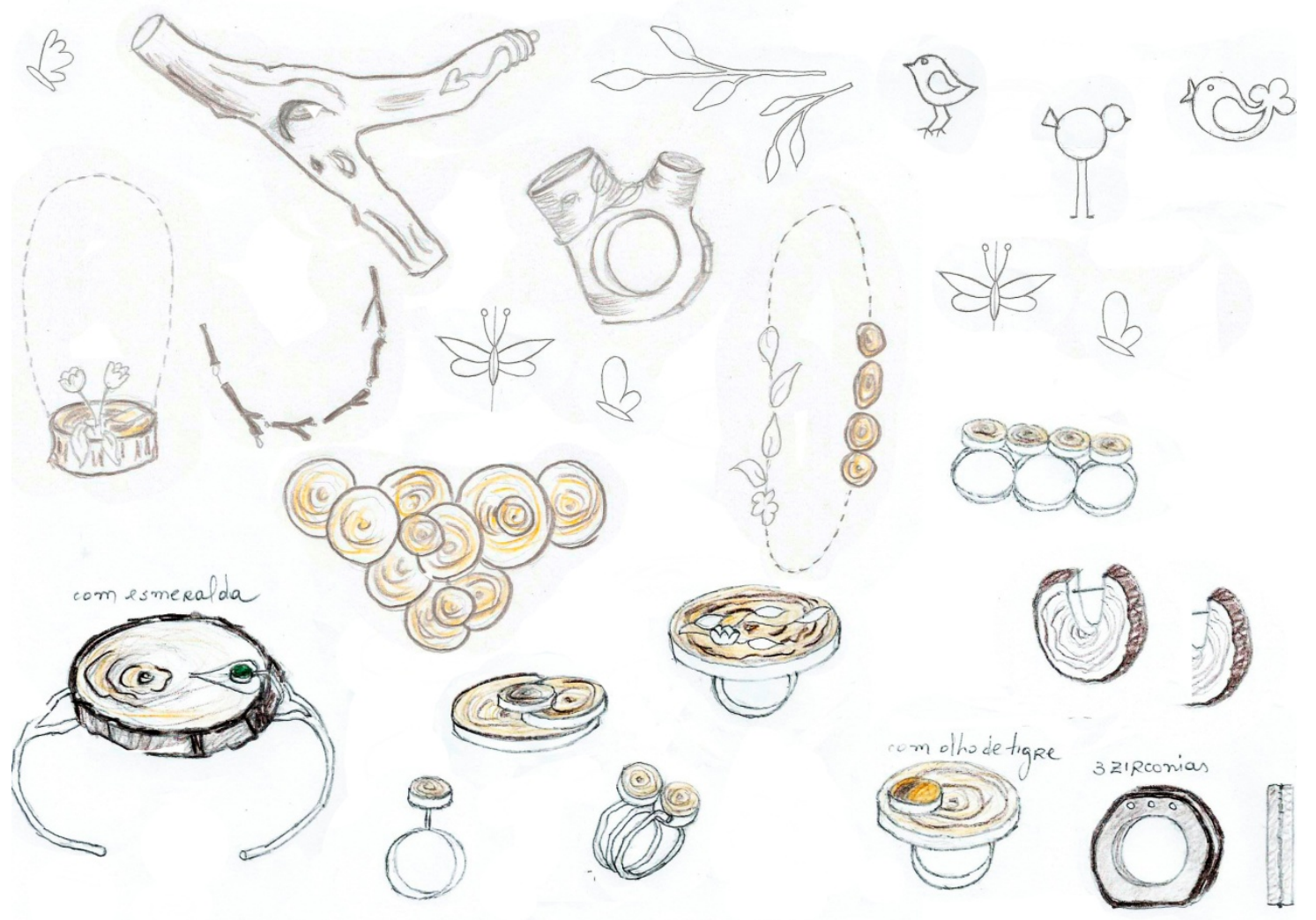

Figura 4 - Geração de alternativas projetuais.

Fonte: Elaborado pelo autor, com base na pesquisa realizada (2013). 


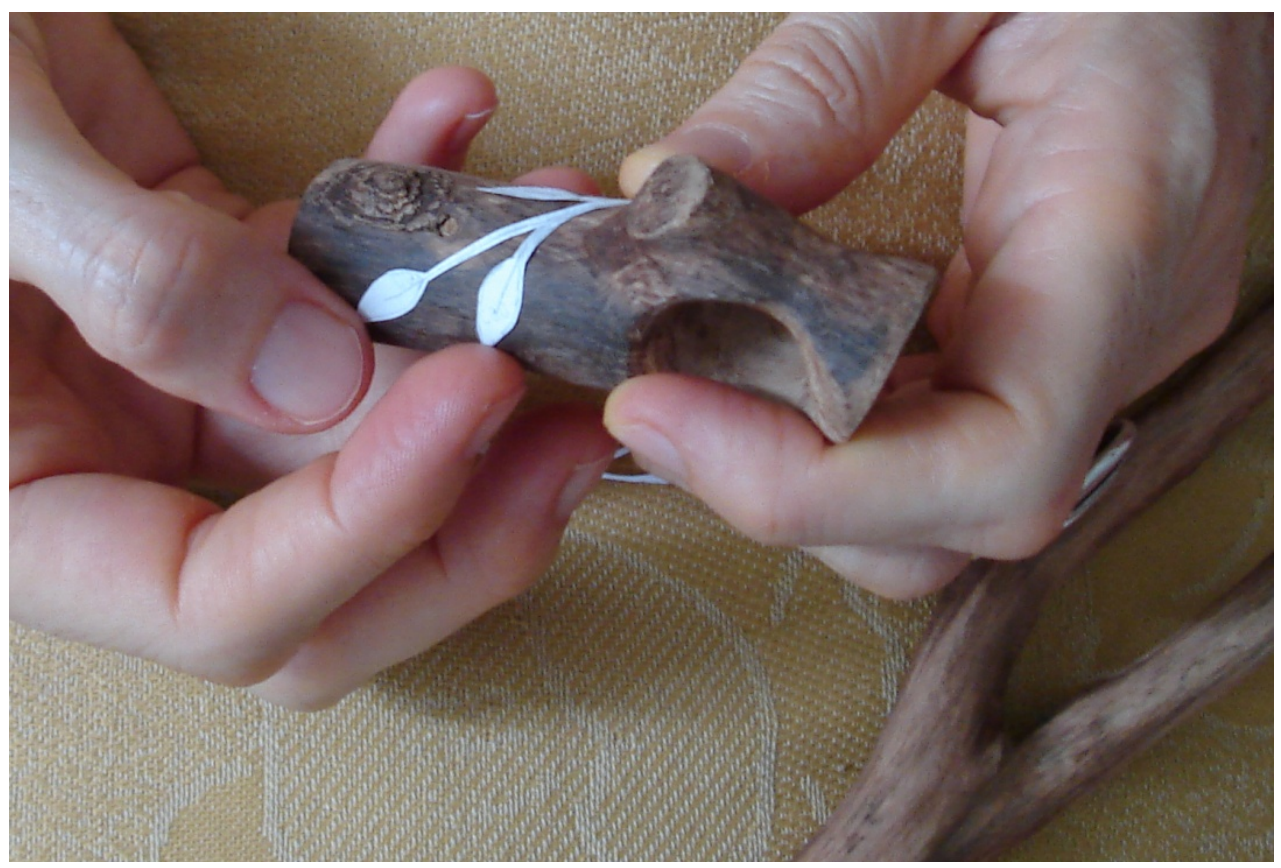

Figura 5- Uso de papel para testar as formas das partes em prata.

Fonte: Elaborado pelo autor, com base na pesquisa realizada (2013). 

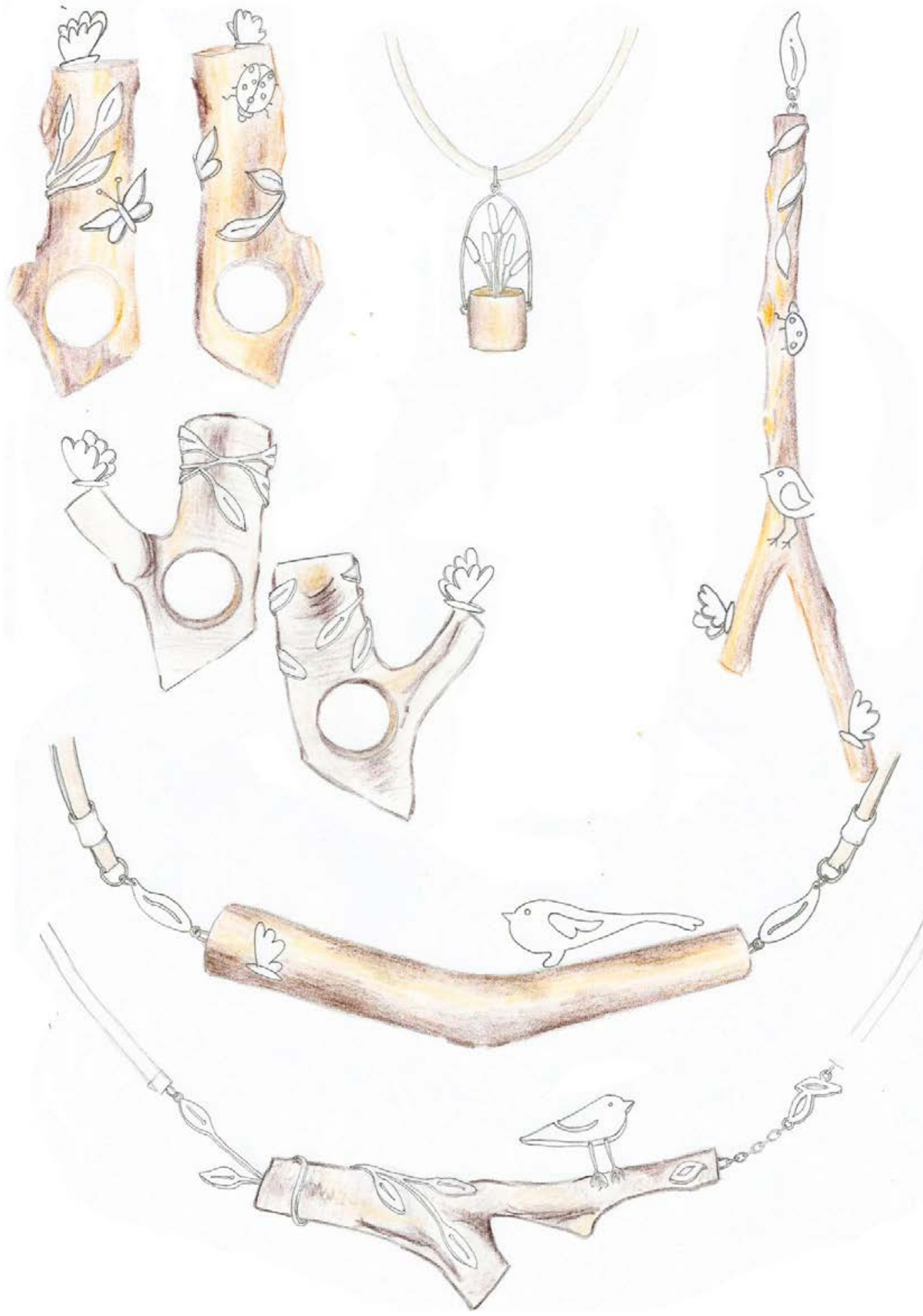

Figuras 6 - Desenho de ilustração do anel Bichinhos, do pingente Caqueiro, do anel Borboleta, do brinco unitário Bichinhos, do colar Andorinha e do colar Pássaro.

Fonte: Elaborado pelo autor, com base na pesquisa realizada (2013). 
Anel borboleta

Chapas para serrar
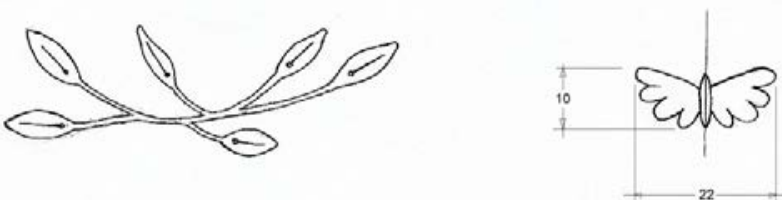

Vista frontal da chapa

Vista lateral da chapa

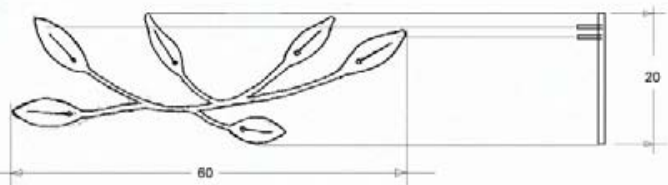

Vista frontal

Vista lateral
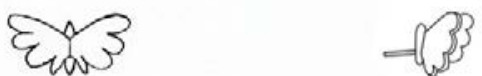

Descrição da peça: anel de madeira e prata, composto por galho de árvore, folhagens em prata e borboleta em prata representando a primavera

Os detalhes em prata sāo serrados em chapa de $1 \mathrm{~mm}$ de espessura.

Processo de fabricaçăo: manual Metal sugerido: prata $950 \quad$ Acabamento do metal: polido Custo aproximado: mão de obra de ourives: $R \$ 46,00$; tratamento da madeira: $R \$ 5,00$; mão de obra para esculpir a madeira: $R \$ 30,00$

Observação: são feitos orificios na madeira para encaixe dos pinos que foram soldados nos galhos.

Estes são fixados na madeira com cola araldite.

\section{Coleção: Primavera}

Temática: sustentabilidade

Tipo de Peça: anel
Tipo de Peça: anel

Escala do desenho: 1:1

Unidade de medida: $\mathrm{mm}$

Figura 7- Desenho técnico e especificações técnicas de um dos modelos. Fonte: Elaborado pelo autor, com base na pesquisa realizada (2013).
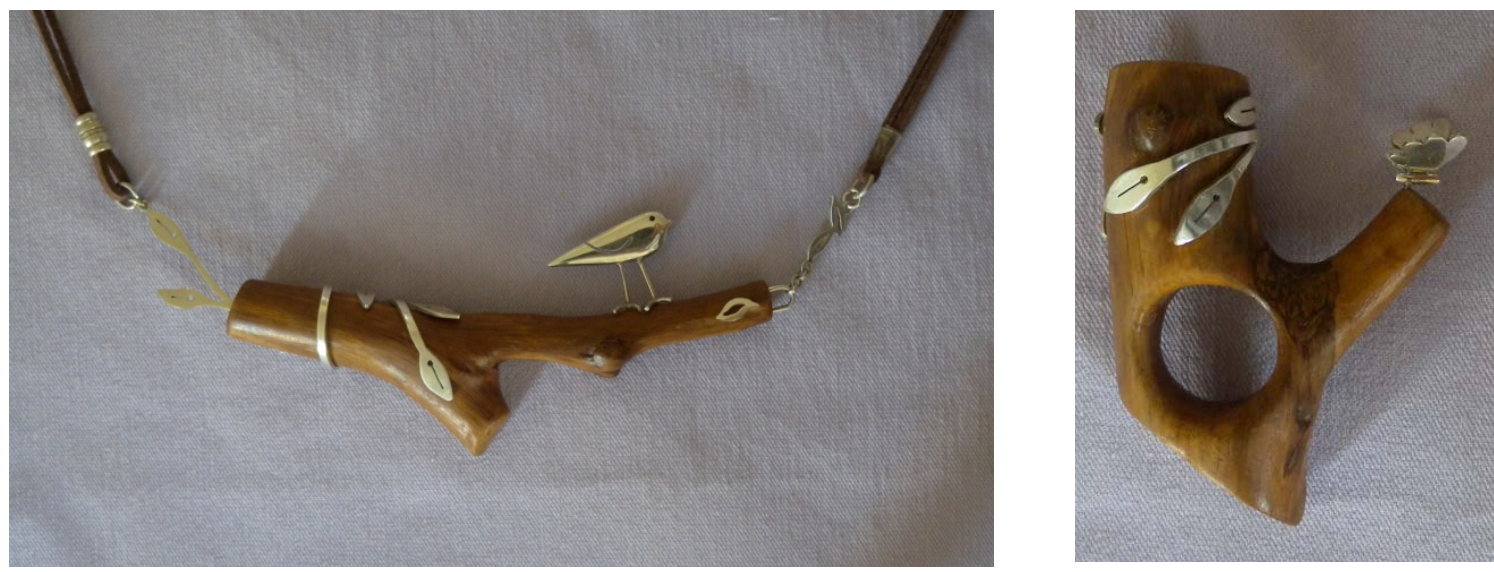

Figuras 8 e 9- Colar pássaro e anel borboleta

Fonte: Elaborado pelo autor, com base na pesquisa realizada (2013). 


\section{3- CONCLUSÃO}

A coleção "Primavera" é composta por dois colares, um brinco, dois anéis e um pingente. Ela utiliza como material predominante, galhos de árvores. Dos galhos secos crescem folhagens e flores e, em sua superfície, pousam pássaros e borboletas em prata, que representam a vida. Em outras palavras, um material que ia para o lixo se transforma em um objeto animado, lúdico.

O estudo expõe os problemas da extração mineral na atualidade e apresenta uma opção de coleção de joias sustentável, mesmo usando um metal. Para isso, apresenta algumas alternativas que podem ser usadas na fabricação das peças e indica de que maneira o fabricante pode conhecer melhor a origem dos metais, das pedras e de suas práticas de extração. A materialização da coleção é a prova de que a sustentabilidade é possível em uma coleção de joias.

O design de joias, assim como todos os ramos do design, tem o dever de ajudar a colaborar na busca de um mundo sustentável. A intenção é disseminar junto a designers, ourives, fabricantes de joias e lapidários, enfim, toda a cadeia produtiva, a importância de trabalhar respeitando a natureza além de poder oferecer aos clientes uma joia ecologicamente correta e socialmente justa. Realizar este estudo foi um grande desafio.

Este trabalho começou em 2013, mas a investigação dos princípios da sustentabilidade aplicada ao design de joias continua na prática profissional da designer, agregando outros materiais descartados como, por exemplo, em trabalho desenvolvido recentemente com PET para a Camapet Bijou, linha da Cooperativa de Coleta Seletiva, Processamento de Plástico e Proteção Ambiental - CAMAPET, localizada em Salvador.

\section{REFERÊNCIAS}

ASHBY, Michel F. Materials and Environement- Materials Selection in Mechanical Design. Butterworth-Heinemann Third edition, 2005.

MANZINI, Ézio; VEZZOLI, Carlo. O Desenvolvimento de Produtos Sustentáveis: os requisitos ambientais dos produtos industriais. São Paulo: EDUSP, 2005.

MORAES, Dijon de. Metaprojeto: o design do design. São Paulo: Blucher, 2010.

MUNARI, Bruno. Como nacen los objetos: Apuntes para uma metodologia projectual. Barcelona: Editorial Gustavo Gilí, 1981.

PAPANEK, Victor. Diseñar para el mundo real: ecologia humana y cambio social. Madrid: Hermann Blume Ediciones, 1977.

Meio Eletrônico

BIS, Eduardo. A principal tendência da atualidade: entenda a urgência do Lowsumerism. Disponível: <http://pontoeletronico.me/2015/lowsumerismentenda/>. Acesso em: 27 jul. 2016.

CARTA CAPITAL. Mineração é a maior responsável por mortes no trabalho ao redor do mundo. Disponível em: <http:// politike.cartacapital. com. br/mineracao-e-a-maiorresponsavel-por-mortes-no-trabalho-ao-redor-do-mundo >. Acesso em 30 jul. 2016.

CENTRO DE TECNOLOGIA MINERAL. Pesquisa inédita do CETEM revela impactos da mineração em 22 estados brasileiros. Disponível em: <http:// 
www.cetem.gov.br/noticias/193-pesquisa-inedita-do-cetem-revela-impactos-damineracao-em-22-estados-brasileiros >. Acesso em 20 jul. 2016.

FÜRST, Omar - Existe extração sustentável de ouro? Disponível em:

<http://bibocaambiental.blogspot.com.br/2013/06/existe-extracao-sustentavel-doouro.html>. Acesso em 7 abri. 2016.

ECO D. Sílvia Blumberg: garimpando joias em canteiros de construções.Disponível em: <http://www.ecodesenvolvimento.org/posts/2012/ janeiro/201co-material-eque-me-procura201d-destaca-a>. Acesso em 30 abril. 2013.

KOTIK. Precious Metal. Disponível em: <http://www.kotik-design.com/>. Acesso em 30 abril. 2016

LAVORATO, Marilena. $\mathbf{O}$ que é consumo responsável? Disponível em: <http://www2.uol.com.br/vyaestelar/consumo_responsavel.htm>. Acesso em 27 jul. 2016.

LEWIS, Arthur. Reciclar...é joia! Disponível em: <http://lewisjoias.blogspot. com.br/> . Acesso em 30 abril de 2013.

MORALES, Lorenzo. O ouro verde da Colômbia. Disponível em: <http://www.bbc.com/ portuguese/celular/noticias/2011/08/110824_ouroverde_rc.shtml>. Acesso em 20 abril. 2013

RECICLOTECA. Recuperação da prata a partir de radiografias. Disponível em: $<$ http://www.recicloteca.org.br/projetos/recuperacao-de-prata-a-partir-deradiografias/>. Acesso em 3 abril. 2014.

PASSOS, Ana. Joias que são obras de arte - Miriam Mamber . Disponível em: <http://www.anapassos.art.br/blog/joias-que-sao-obras-de-arte-miriam-mamber/> Acesso em 20 maio. 2013.

DI-CONEXIONES. Mana Bernardes: utilizando el diseño para convertir residuos en joyas. Disponível em: < http://www.di-conexiones.com/mana-bernardes-utilizando-eldiseno-para-convertir-residuos-en-joyas/>. Acesso em 6 abril. 2013. 